\title{
Genesis, frequency, and diagnostic significance of ejection sound in adults with tetralogy of Fallot
}

\author{
C. Edwin Martin, P. S. Reddy, Donald F. Leon, and James A. Shaver \\ From the Department of Medicine, Division of Cardiology, University of Pittsburgh School of Medicine, \\ Pittsburgh, Pennsylvania, U.S.A.
}

The clinical records of 24 adult patients with tetralogy of Fallot showed an ejection sound to be present in I3, I2 of whom had significant pulmonary valvular stenosis. In IO patients with infundibular obstruction only, an ejection sound was recorded in one. The pulmonary closure sound was recorded in all patients having an ejection sound, but in only 4 of II patients without an ejection sound. The ejection sound was clearly recorded with a catheter-tip micromanometer in the proximal pulmonary artery where it occurred coincident with an anacrotic notch, $40 \mathrm{msec}$ after the rise of pulmonary artery pressure. Angiograms showed doming of the stenotic pulmonary valve. A pulmonary ejection sound was recorded in presystole in one patient when the right ventricular end-diastolic pressure, due to a forceful atrial contraction, exceeded the pulmonary artery pressure; during a short period of atrioventricular dissociation, the timing of the ejection sound varied as a function of the PR interval. Therefore an ejection sound occurs frequently in adults with tetralogy of Fallot, where it is a diagnostically useful sign, indicating the presence of pulmonary valvular stenosis.

In infants and children with tetralogy of Fallot the incidence of ejection sounds varies directly with the severity of the pulmonary outflow obstruction. Thus, ejection sounds are stated to be rare in milder forms of tetralogy of Fallot but are frequent in severe and extreme forms (Vogelpoel and Schrire, I960b; Lafargue et al., 1967; Perloff, 1970). In severe tetralogy of Fallot an ejection sound is thought to originate from a dilated overriding ascending aorta which is not a feature of milder forms (Leatham, 1958; Perloff, 1970). However, in adult patients with either less severe forms of tetralogy of Fallot or in whom the course had been altered by palliative operation, we commonly noted the presence of an ejection sound. There was no apparent correlation between the severity and the presence or absence of an ejection sound which did appear to be present, however, in those patients with valvular pulmonary stenosis. In 8 cases studied prospectively since making this observation, we have been able to make a correct precatheterization diagnosis in 7 , i.e. tetralogy of Fallot with or without valvular pulmonary stenosis. Consequently the present study was designed to define more clearly the significance of an ejection sound in adult patients with tetralogy of Fallot.

Received 3 August 1972.

\section{Subjects and methods}

Records of all patients with the diagnosis of tetralogy of Fallot who were studied at this institution since June I963 were reviewed. For purposes of this study tetralogy of Fallot was defined as the combination of a large ventricular septal defect and right ventricular outflow obstruction resulting in equal right and left ventricular pressures. Patients with a small ventricular septal defect and/or mild right ventricular outflow obstruction were therefore excluded. The phonocardiograms were reviewed by two of the authors (J.A.S. and C.E.M.) and were divided into two groups based on the presence or absence of ejection sound. Satisfactory phonocardiograms were available in 22 patients. Two additional patients (Cases 2 and 24) were accepted without preoperative phonocardiograms because a detailed description of the physical findings by a senior member of the cardiology faculty was available for both.

The haemodynamic, angiographic, and surgical data were then reviewed and grouped according to the presence or absence of pulmonary valvular stenosis. The type of right ventricular outflow tract obstruction was determined by pressure measurements during cardiac catheterization, by angiography, and in 16 patients by direct examination at operation. Patients were classified as having pure valvular stenosis when an additional pressure gradient across the infundibulum was not demonstrable even though the infundibulum may have appeared narrow by angiography or at operation. Angiograms 
and/or reports of surgical visualization of the valve were available for all patients. The ejection sound (ES) was then evaluated in terms of its sensitivity, specificity, and overall correctness in predicting the presence or absence of pulmonary valvular stenosis (PVS) according to the following formulae:

$$
\begin{aligned}
& \text { Sensitivity }=\frac{\text { Patients } \text { with both PVS and ES }}{\text { Total with PVS }} \\
& \text { Specificity }=\frac{\text { Patients } \text { with no ES and no PVS }}{\text { Total without PVS }}
\end{aligned}
$$

Overall correctness $=\frac{\text { True positives plus true negatives }}{\text { Total patients }}$

\section{Special catheterization studies}

Special catheterization studies were performed on 3 patients who were studied prospectively. Sound-pressure correlations of the ejection sound were made with Dallons-Telco catheter-tip micromanometers. External sound was recorded along with selected sound pressure measurements from the right and left ventricle, pulmonary artery, central aorta, and, in one instance, from the right atrium. One patient with valvular pulmonary stenosis with intact ventricular septum was studied in a similar manner. The tracings were analysed as previously described for evaluation of heart sounds in relation to pressure events (Whittaker et al., 1969).

TABLE I Summary of clinical findings in patients with tetralogy of Fallot

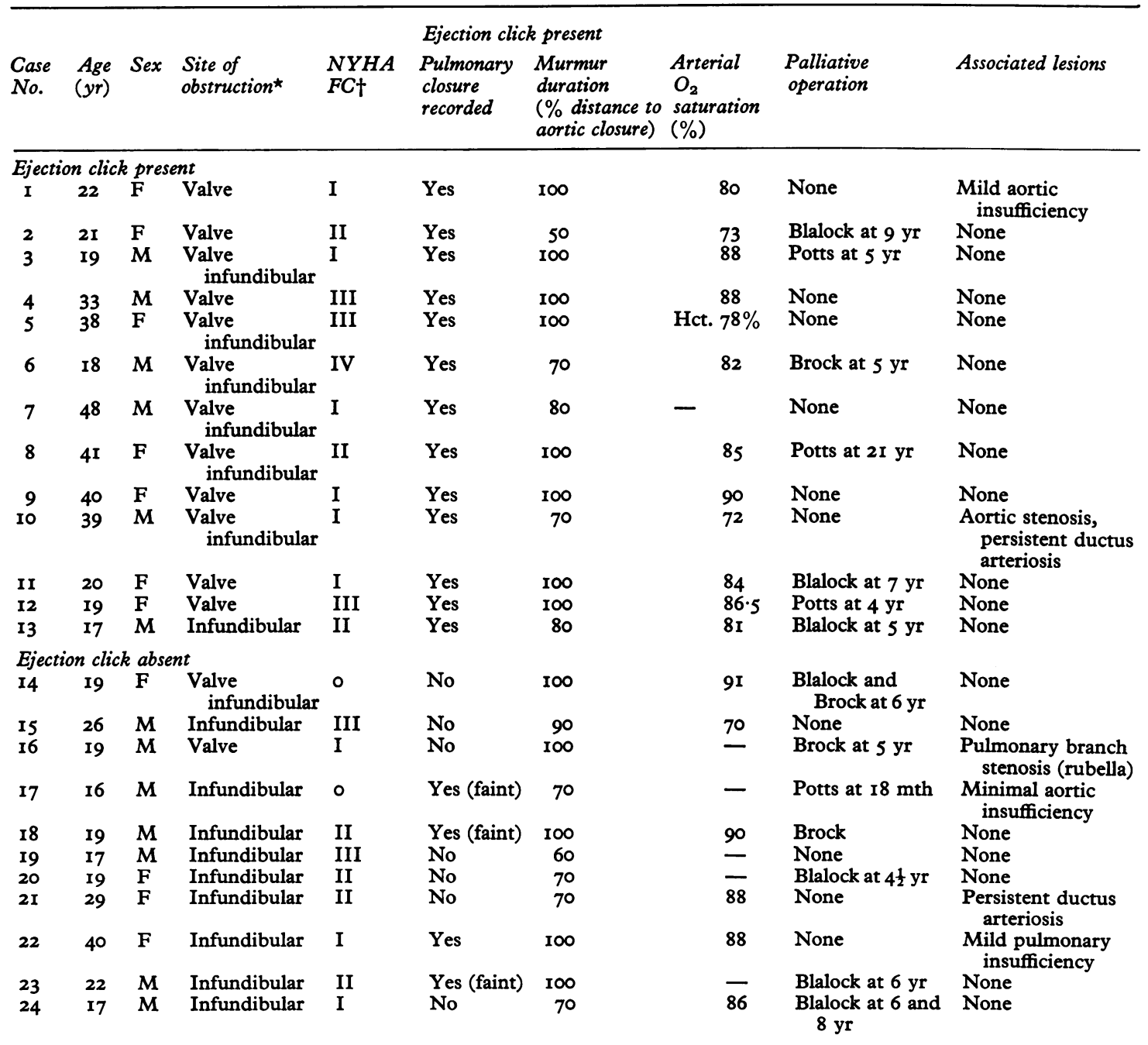

«In patients with only valve obstruction the infundibular appeared narrow on the angiogram and at operation but no pressure gradient was demonstrated across the infundibular outflow tract.

$\dagger$ New York Heart Association functional classification. 


\section{Results}

Studies were made on 14 male and 10 female patients ranging in age from 16 to 48 years (mean 26 years). The clinical and haemodynamic data are summarized in Table I. Fourteen had pulmonary valve stenosis comprising part or all of the obstruction; I4 had previous palliative procedures; and 6 had associated cardiac anomalies. All but one patient (Case 22) had a history of cyanosis which was still present at least intermittently in 6 patients (Cases 2, 5, 6, 15, 19, 21). Two patients (Cases 14 and 17) were asymptomatic at the time of study and one (Case 6) was severely symptomatic with dyspnoea and fatigue at rest. Nine were considered to be in the New York Heart Association Functional Class I, 7 in Functional Class II, and 5 in Functional Class III.

\section{Relation between ejection sound and type of right ventricular outflow obstruction}

An ejection sound was present in 13 patients (Fig. I) (Table 2). In 12 patients with an ejection sound there was pulmonary valve stenosis, associated with significant infundibular obstruction in 6 . The pulmonary valve was normal in one patient in whom an ejection sound was present. An ejection sound was absent in I I patients (Fig. 2) in 9 of whom there was no pulmonary valve stenosis. Of the 2 patients with pulmonary valve stenosis and no ejection sound, one had associated infundibular obstruction and one had additional pulmonary branch stenosis. The association between the site of obstruction and the presence or absence of an ejection sound is shown in Table 2. Using the numbers from Table 2, calculations were made of sensitivity, specificity, and overall correctness for the pulmonary ejection sound as an indicator of the presence or absence of pulmonary valvular stenosis in adult tetralogy of Fallot, therefore:

$$
\text { Sensitivity }=\frac{\text { Number } \text { with both PVS and ES }}{\text { Total with PVS }}=\frac{12}{I_{4}}=86 \%
$$

with a $14 \%$ incidence of false negatives

$$
\text { Specificity }=\frac{\text { Number } \text { with neither PVS nor ES }}{\text { Total without PVS }}=\frac{9}{10}=90 \%
$$

with a $10 \%$ incidence of false positives

Overall correctness $=\frac{\text { True positives and true negatives }}{\text { Total number }}$

$$
=\frac{12+9}{24}=88 \%
$$

The interval from the $Q$ wave of the electrocardiogram to the ejection sound (Q-ES) varied from 80
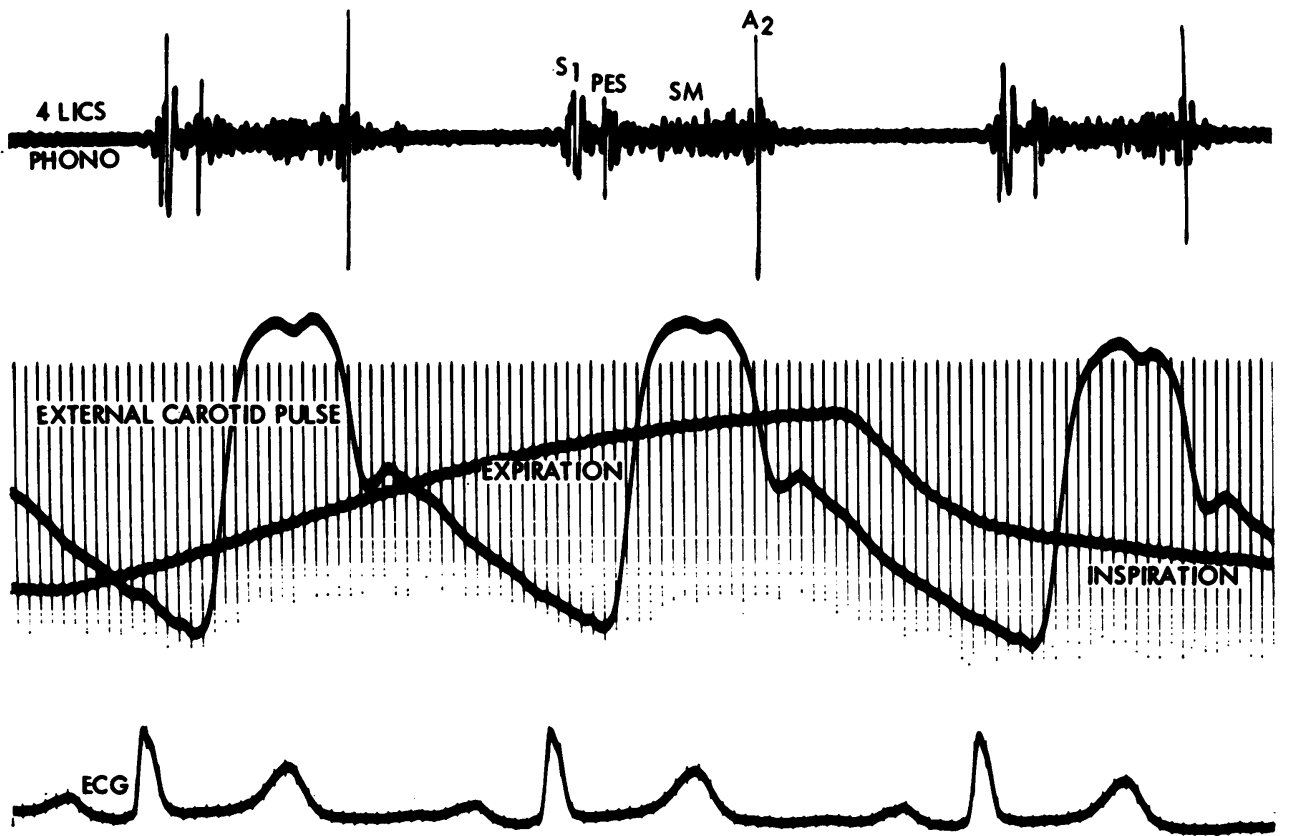

FIG. I Phonocardiogram from Case 12 with valvular pulmonary stenosis and an ejection sound (PES). The Q-PES interval measures 120 msec. The systolic murmur (SM) extends to the aortic closure sound $\left(A_{2}\right)$. A faint pulmonary closure sound is recorded only in the first complex, separated from $A_{2}$ by $85 \mathrm{msec}$. In this and subsequent phonocardiograms paper speed = $100 \mathrm{~mm} / \mathrm{sec}$ and time lines $=20 \mathrm{msec}$. 
TABLE 2 Relation of ejection sound to selected clinical characteristics

\begin{tabular}{|c|c|c|c|c|c|c|}
\hline \multirow{2}{*}{$\begin{array}{l}\text { Ejection sound } \\
\text { Present }(\mathrm{N}=\mathrm{I} 3) \\
\text { Absent }(\mathrm{N}=\mathrm{I} \mathrm{I})\end{array}$} & \multicolumn{2}{|c|}{$\begin{array}{l}\text { Pulmonary valve } \\
\text { stenosis }\end{array}$} & \multicolumn{2}{|c|}{$\begin{array}{l}\text { Pulmonary closure } \\
\text { recorded }\end{array}$} & \multicolumn{2}{|c|}{$\begin{array}{l}\text { Previous palliative } \\
\text { operation }\end{array}$} \\
\hline & $\begin{array}{l}\text { Present } \\
\text { I2 } \\
2\end{array}$ & $\begin{array}{l}\text { Absent } \\
\text { I } \\
9\end{array}$ & $\begin{array}{c}\text { Yes } \\
13 \\
4\end{array}$ & $\begin{array}{l}\text { No } \\
0 \\
7\end{array}$ & $\begin{array}{c}\text { Yes } \\
7 \\
7\end{array}$ & $\begin{array}{c}\text { No } \\
6 \\
4\end{array}$ \\
\hline Total (24) & 14 & 10 & 17 & 7 & 14 & Io \\
\hline
\end{tabular}

to $130 \mathrm{msec}$ (mean Ior msec), excluding one (Case I0) in which it occurred before the onset of QRS (see below). Externally the ejection sound was usually recorded best at the upper left sternal border and showed no consistent variation with respiration (Fig. 3).

Relation between ejection sound and pulmonary closure sound

The pulmonary component of second heart sound $\left(P_{2}\right)$ was recorded or heard in 17 of 24 patients (Table 2). It was recorded in all patients in whom an ejection sound was present, but was absent in 7 of I I patients who did not have an ejection sound. $P_{2}$ was present in 12 of 14 patients with valvular pulmonary stenosis. In Io patients with only infundibular stenosis in contrast, $\mathbf{P}_{\mathbf{2}}$ was absent in 5 , recorded intermittently in 3 , and recorded well in only 2. Splitting between aortic closure and $P_{2}$ ranged from 30 to II $5 \mathrm{msec}$ (mean 7I $\mathrm{msec}$ ) and showed no consistent narrowing during expiration.

\section{Relation between previous palliative operation} and an ejection sound

Of 14 patients with previous palliative operations, an ejection sound was present in 7 and absent in 7 (Table 2). A history of previous palliative operation showed no relation therefore to the presence or absence of an ejection sound.

\section{Results of sound pressure correlation studies}

Sound pressure recordings were made from the ventricles and central aorta in 3 patients. The catheter was then advanced into the pulmonary artery and simultaneous pulmonary artery and left ventricular or central aorta measurements were made. In the central aorta and ventricles the first heart sound was clearly recorded and was accompanied by a transient
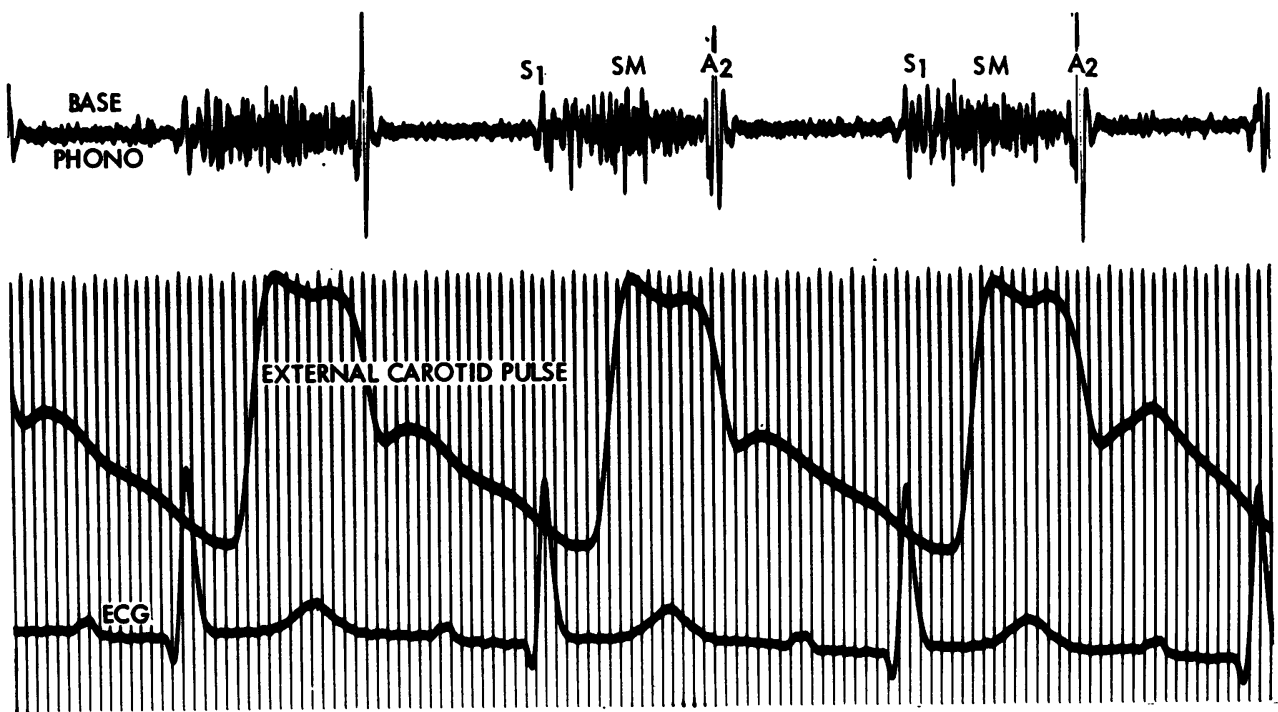

FIG. 2 Phonocardiogram from Case 10 with tetralogy and pulmonary infundibular stenosis. The absence of an ejection and a pulmonary closure sound and the presence of a long systolic murmur are characteristic of this type of tetralogy which is of mild to moderate severity. 

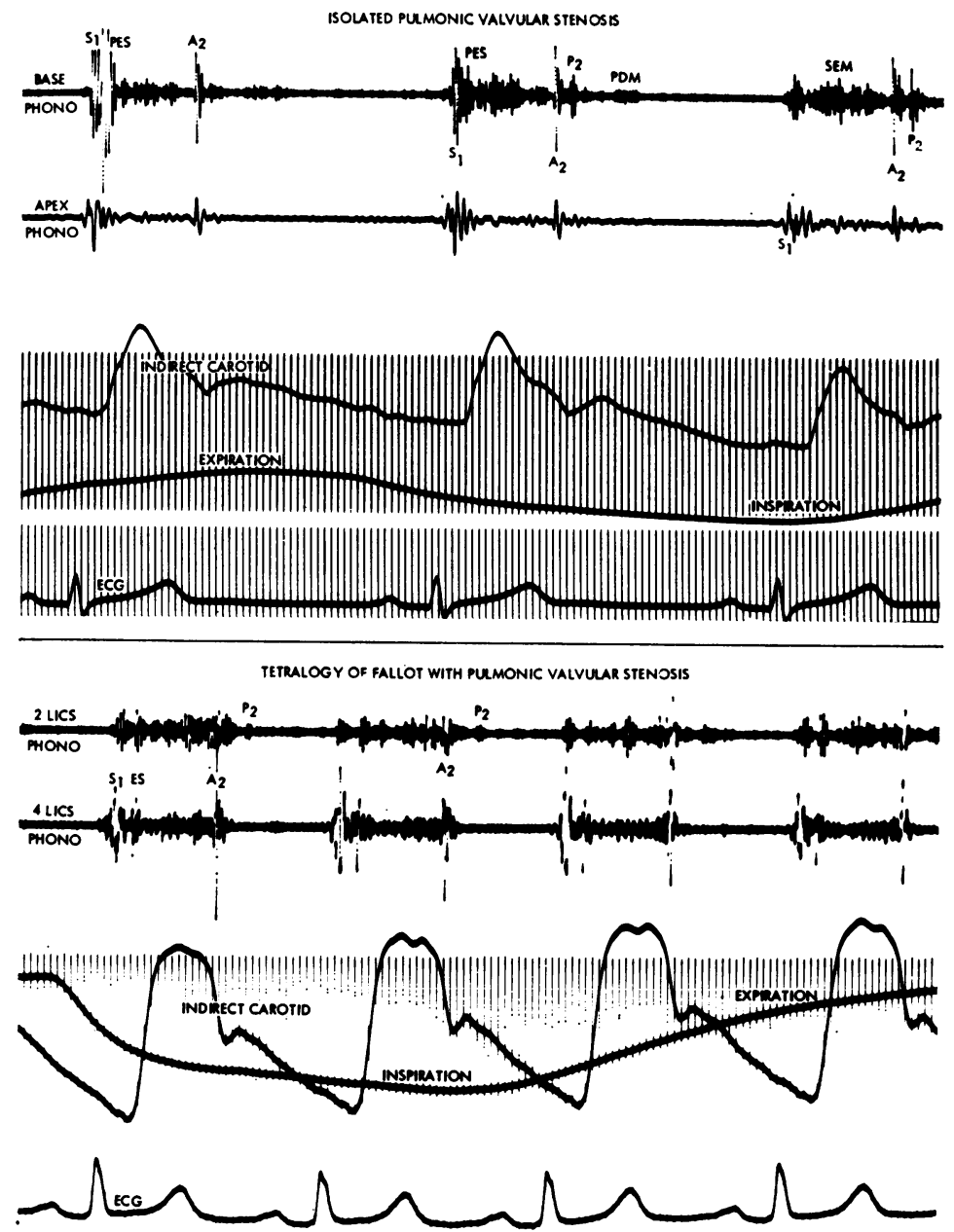

FIG. 3 Phonocardiograms demonstrating the effect of respiration on the intensity of an ejection sound. In pulmonary valvular stenosis with an intact ventricular septum (top panel), the ejection sound decreases in intensity during inspiration. In pulmonary valvular stenosis associated with tetralogy of Fallot (bottom panel), no respiratory variation in intensity of the ejection sound was noted. Respirations are recorded with a thermistor.

in the central aorta pressure tracing (Fig. 4-5). The ejection sound was recorded poorly in the ventricles and central aorta. It was recorded externally after the onset of pressure rise in the central aorta but was not accompanied by a transient in the pressure tracing. When the micromanometer was advanced into the pulmonary artery, a prominent pulmonary ejection murmur was recorded. The ejection sound on the external recording diminished in intensity but was clearly recorded from the pulmonary artery catheter. It occurred 30 to $40 \mathrm{msec}$ after the onset of pressure rise in the pulmonary artery accompanied by an anacrotic notch (Fig. 5).
In one patient (Case IO) a sharp ejection sound was recorded before the onset of the QRS complex, I 50 msec after the $\mathbf{P}$ wave. It was best recorded externally in the second intercostal space and poorly at the apex (Fig. 6). This patient had associated aortic valvular stenosis with a $40 \mathrm{~mm}$ left ventricular central aorta gradient and a persistent ductus arteriosis. The relation of the presystolic sound to atrial contraction was shown during a transient period of atrial-ventricular dissociation which followed two spontaneous premature ventricular contractions (Fig. 6). With a normal PR interval a prominent presystolic sound was recorded at the base. During 

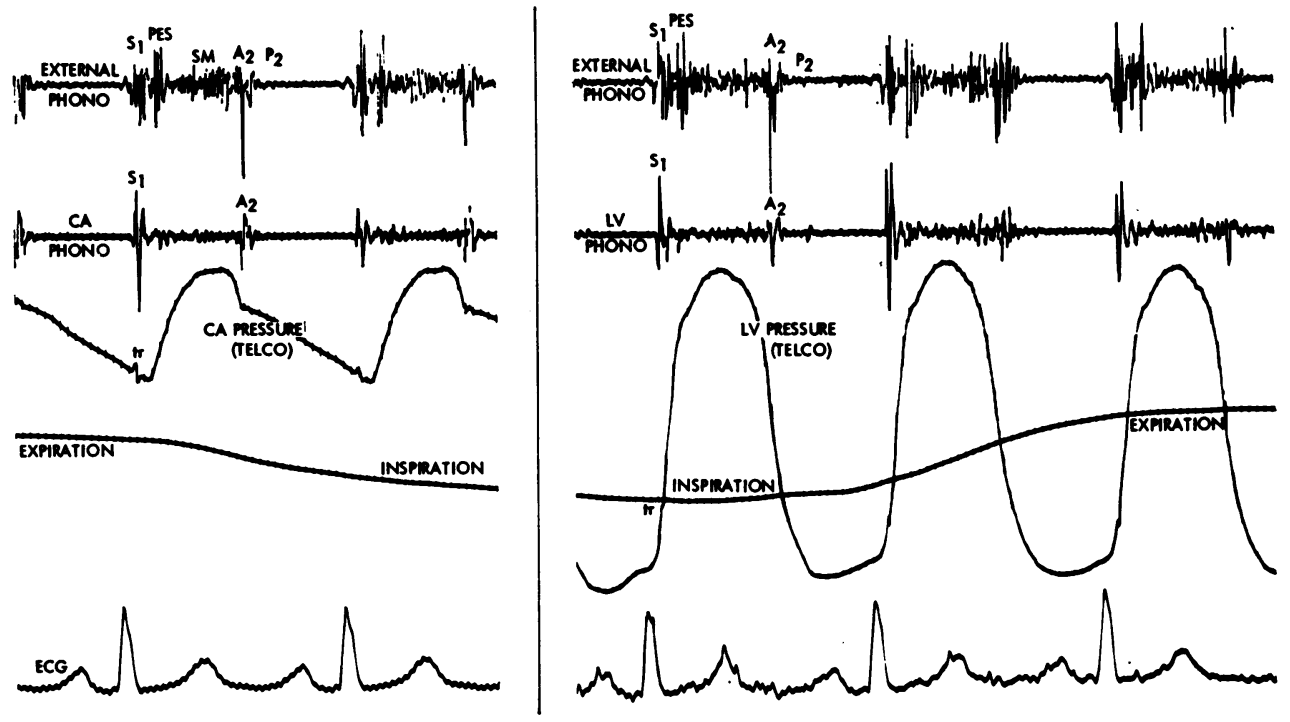

FIG. 4 Correlation of sound and pressure using a catheter-tip micromanometer in Case II who has tetralogy of Fallot, and valvular pulmonary stenosis. On the left panel, the catheter is placed immediately above the aortic valve $(C A)$. A prominent first heart sound $\left(S_{1}\right)$ and a transient $(t r)$, but no systolic murmur (SM) or ejection sounds are recorded by the $C A$ microphone. An ejection sound (PES) is recorded externally. On the right panel, the catheter has been advanced into the left ventricle $(L V)$. A transient (tr) is seen on the $L V$ pressure trace coincident with $S_{1}$. An ejection sound is recorded externally but not from the $L V$.

subsequent beats the timing of the sound appears as a function of the PR interval, occurring in early systole when the PR interval is short and gradually emerging into presystole as the PR interval lengthens. During catheterization the sound was shown to occur when the right atrial a wave of $8 \mathrm{~mm}$ amplitude (and therefore right ventricular end-diastolic pressure) exceeded the pulmonary artery pressure (Fig. 7). When the patient experienced a vasovagal attack with diaphoresis and nausea during catheterization, the presystolic sound disappeared and the right ventricular a wave dropped below the pulmonary artery end-diastolic pressure.

In a patient with pulmonary valvular stenosis and an intact ventricular septum, an ejection sound occurred 30 to $40 \mathrm{msec}$ after pulmonary artery right ventricular pressure crossover, coincident with the anacrotic notch in the pulmonary artery (Fig. 8).

\section{Discussion}

An ejection sound may originate from the aortic root, from the pulmonary outflow tract, or from an abnormal aortic or pulmonary valve (Wolferth and Margolies, 1945; Leatham and Vogelpoel, 1954; Whittaker et al., 1969; Hultgren et al., 1969). In severe tetralogy of Fallot it is thought to arise from a dilated, anteriorly overriding ascending aorta.
Another explanation is required for the high frequency of ejection sounds in the present group of patients who seemed to have a less severe form of tetralogy, in which a much dilated anteriorly overriding aorta and an aortic ejection sound are not present (Vogelpoel and Schrire, I960b; Gotsman, 1966; Friesinger and Bahnson, 1966).

We considered this group of patients to have less severe forms of tetralogy on the basis of survival into adulthood with only moderate symptoms, long systolic murmurs, and lack of severe cyanosis (Vogelpoel and Schrire, 1960b). This distinction is not easily made since some patients with severe pulmonary outflow obstruction may do well clinically because of extensive development of bronchial collateral circulation (Bing, Vandam, and Gray, 1947; Higgins and Mulder, 1972). In addition, the degree of infundibular obstruction may increase with time, accounting for a delayed appearance of symptoms in some patients (Gotsman, I966).

It was also considered that previous palliative operation might have obscured a very severe tetralogy with a dilated overriding aorta in some of our patients. If an ejection sound originated from a dilated aorta in these patients, however, one would expect a higher incidence of ejection sounds among those patients who had previous palliative 


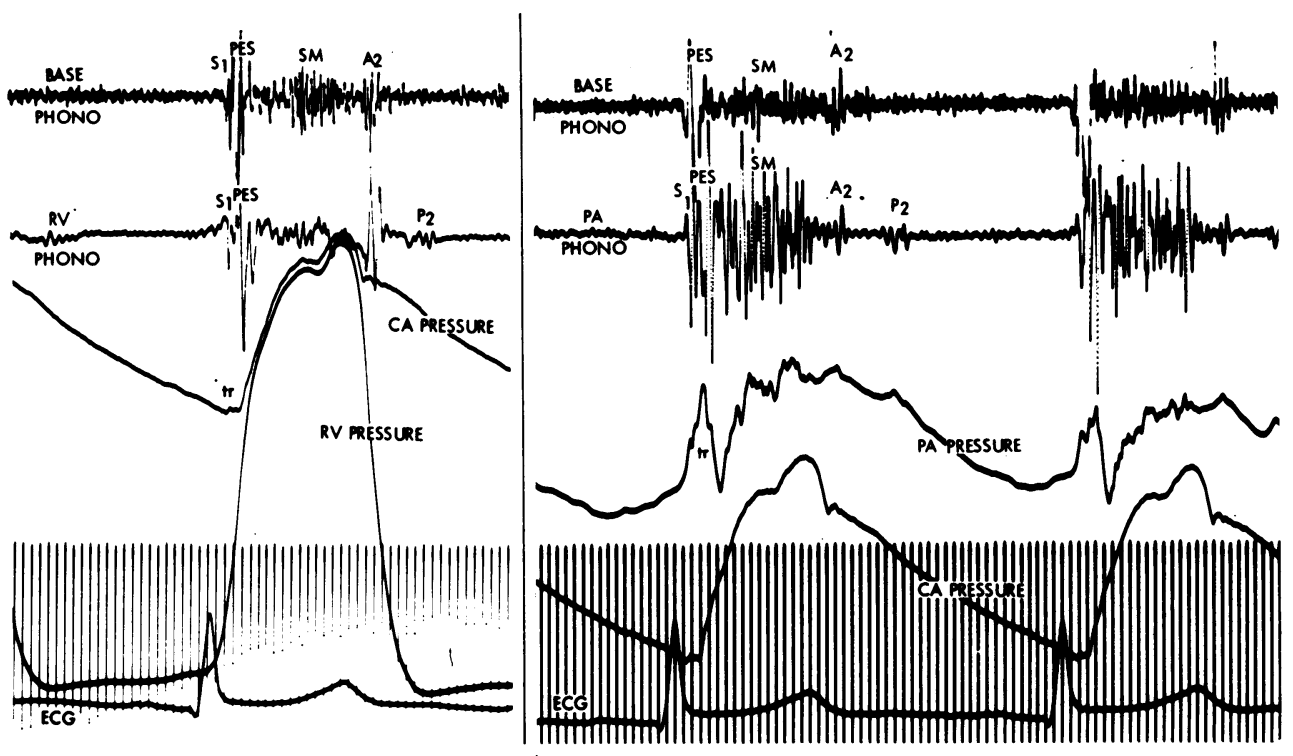

FIG. 5 Sound-pressure correlations with catheter-tip micromanometer (Case 8). Left panel: right ventricular $(R V)$ and central aorta $(C A)$ pressures are recorded by equisensitive catheters. $A$ transient (tr) appears on the $C A$ pressure trace coincident with $S_{1}$. A tr does not accompany the ejection sound (PES) which is recorded by both the external and $R V$ phonos. The $R V$ phono is positioned immediately under the pulmonary valve. Right panel: The $R V$ catheter has been advanced to the pulmonary artery $(P A)$. PES is now less prominent on the external phonocardiogram. It is recorded along with a loud systolic murmur by the $P A$ microphone, and is coincident with tr on the $P A$ pressure trace. Sensitivity of the $P A$ catheter has been increased and the $C A$ pressure trace has been lowered.

operations (McKusick, I958). Patients who had palliative operations, however, were found to be equally divided into the groups with and without an ejection sound (Table 2).

Tetralogy of Fallot patients with pulmonary valvular stenosis have been noted previously (Vogelpoel and Schrire, I960b), as in the present study, to have a higher incidence of a recordable pulmonary valve closure sound. This indicates that the pulmonary valve, though stenotic, was mobile and that the diastolic pulmonary artery pressure was adequate to account for a pulmonary closure sound.

The aetiology and behaviour of the ejection sound in adults with tetralogy of Fallot may be studied by comparing it with that of patients with pulmonary stenosis and an intact ventricular septum. An ejecjection sound is conspicuously absent in isolated infundibular pulmonary stenosis, but is a usual feature of mild and severe grades of valvular stenosis, though in more severe forms it may merge with the first heart sound (Vogelpoel and Schrire, I960a; Gamboa, Hugenholtz, and Nadas, I964; Perloff, 1964). In isolated pulmonary valve stenosis, an ejec- tion sound has been postulated to arise from the valve proper or from the snapping of the dilated poststenotic portion of the pulmonary artery during early ejection (Leatham and Weitzman, 1957). Recent studies using simultaneous recordings of electrocardiographic, angiographic, and sound pressure recordings have shown the ejection sound to appear simultaneously with an abrupt doming of the stenotic valve, before the wall of the pulmonary artery distends (Hultgren et al., 1969). Therefore, a mobile doming stenotic valve appears to be the primary cause of the ejection sound in pulmonary valve stenosis. An angiogram showing doming of the stenotic pulmonary valve in a patient (Case II) with tetralogy of Fallot, pulmonary valve stenosis, and an ejection click is shown in Fig. 9. At the onset of ejection the upward excursion of the stenotic valve was seen to check abruptly during angiography as has been described in patients with aortic and isolated pulmonary valvular stenosis (Epstein et al., 1965; Whittaker et al., 1969; Hultgren et al., 1969). This is the likely explanation for an ejection sound in adult patients with tetralogy of Fallot in whom 


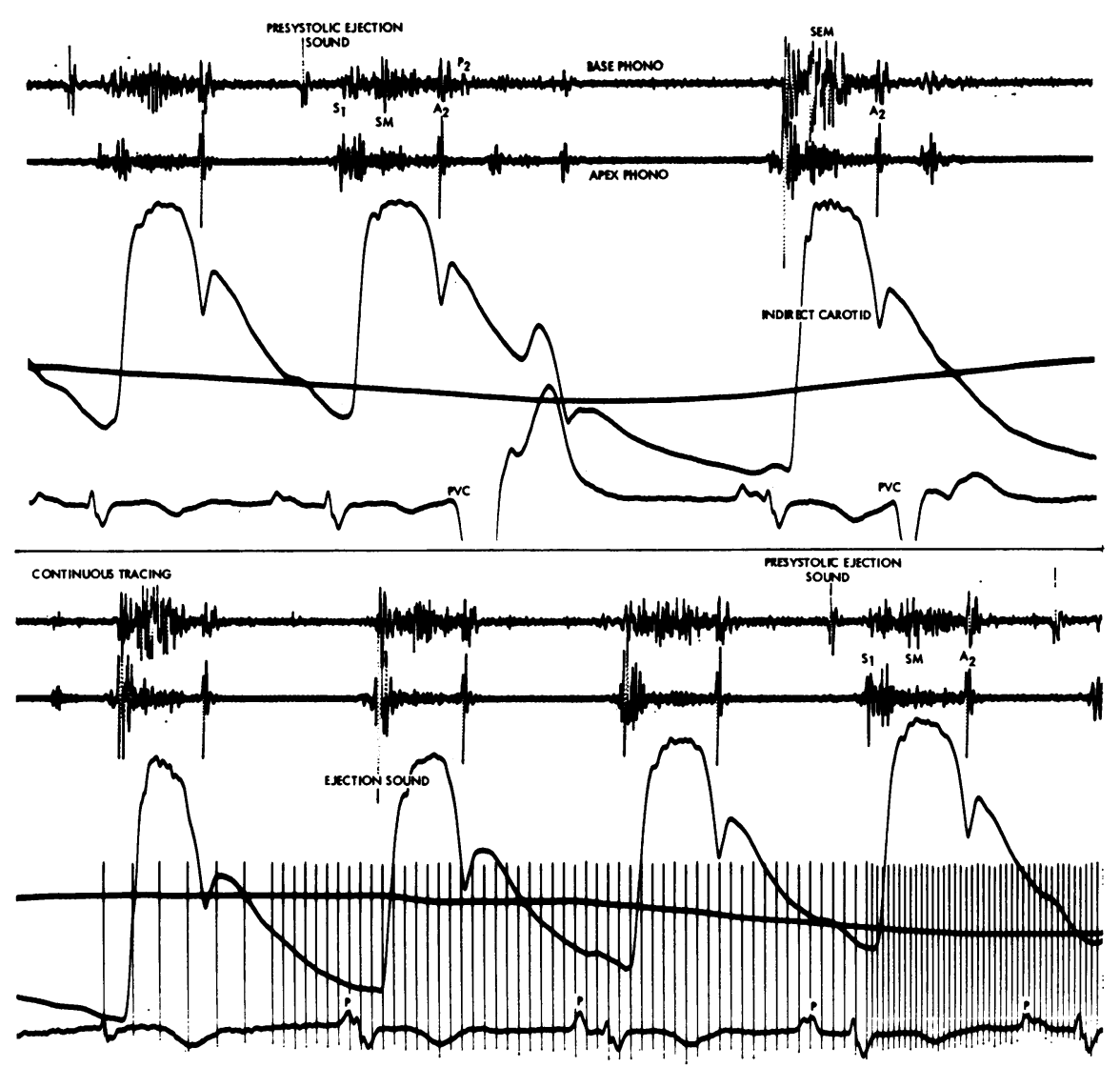

FIG. 6. External phonocardiogram (Case Io) showing a presystolic ejection sound during sinus rhythm (top panel, first two complexes). When a transient junctional escape rhythm occurs after the premature ventricular contraction (PVC) the ejection sound disappears from presystole. The presystolic sound reappears (bottom panel) with gradual lengthening of the PR interval; following the $p$ wave by $120 \mathrm{msec}$. Time lines $=40 \mathrm{msec}$ in middle of bottom panel and $20 \mathrm{msec}$ on right bottom panel.

post-stenotic dilatation of the pulmonary artery is not a usual feature.

Although ejection sounds of isolated pulmonary valve stenosis often decrease in intensity during inspiration (Reeve, 1966), this was not observed in our patients with tetralogy of Fallot (Fig. 3). In isolated pulmonary valve stenosis, the pressure difference between the right ventricle and the pulmonary artery may narrow when the right atrial a wave is accentuated by an inspiratory increase in venous return. As a result the pulmonary valve is already in a domed position at the onset of right ventricular systole during inspiration and the intensity of the ejection sound is diminished (Hultgren et al., 1969).

In tetralogy of Fallot, in contrast, the right atrial a wave is not accentuated (Hoffman et al., 1960). The large ventricular septal defect provides a runoff for the increased venous return into the left ventricle, thereby preventing a significant inspiratory increase in right ventricular end-diastolic pressure. Palliative shunting procedures which direct flow into the pulmonary artery may also prevent an obvious inspiratory drop in pulmonary artery pressure in some patients. Either or both of these factors could explain the lack of respiratory variation which was evident in this group of patients.

The ejection sound of isolated valvular pulmonary stenosis may occur in presystole due to a forceful right atrial contraction which raises right ventricular end-diastolic pressure above that of the pulmonary artery (Hultgren et al., 1969). Though this phenomenon normally does not occur in tetralogy of Fallot because the 'right atrial kick' is not prominent (Hoffman et al., 1960), it was present in Case 10 

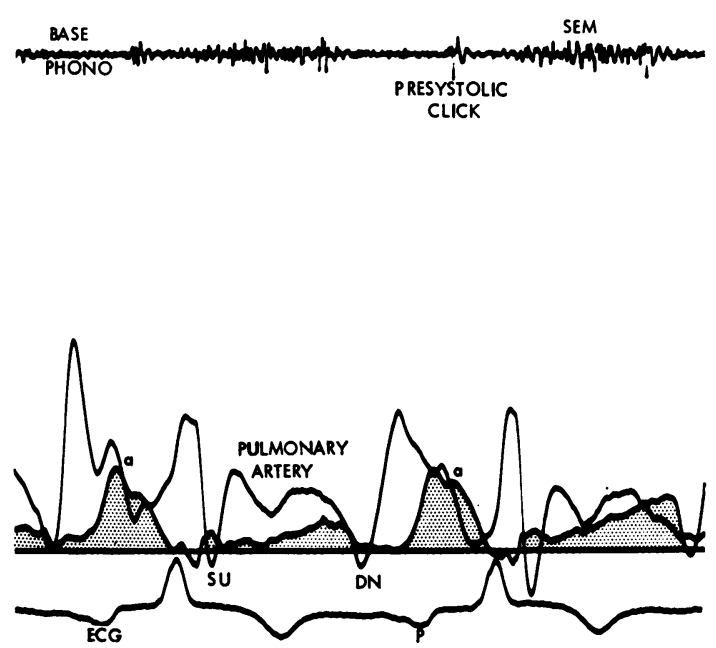

FIG. 7 Simultaneous phonocardiograms, pulmonary arterial and right atrial pressure (dotted area) from Case 10. The presystolic click occurs when the right atrial $a$ wave and therefore right ventricular enddiastolic pressure exceeds pulmonary artery diastolic pressure. The dicrotic notch $(D N)$ and systolic upstroke (SU) of the pulmonary artery pressure trace are falsely low reflecting catheter artefact. who had associated aortic stenosis which may decrease diastolic left ventricular compliance. This sound was a function of the timing of atrial systole as shown in Fig. 6. During escape rhythm, in the absence of a preceding atrial contraction, it appeared as a systolic ejection sound, but returned to presystole as the PR interval progressively lengthened. The haemodynamic determinants of this behaviour were clarified during cardiac catheterization. The presystolic ejection sound occurred when the right atrial a wave (and right ventricular end-diastolic pressure) abruptly rose above pulmonary artery diastolic pressure (Fig. 7). It disappeared completely from presystole during a vasovagal attack when the right atrial a wave dropped below the pulmonary artery end-diastolic pressure.

\section{Sound pressure correlations of ejection sound}

Previous studies in this laboratory have shown the usefulness of sound pressure correlations with catheter-tip micromanometers for the precise delineation of heart sounds (Whittaker et al., 1969; Thompson et al., 1970. Ejection sounds of valvular origin in aortic stenosis have been distinguished from those of aortic root origin, in that the latter coincide precisely with the onset of pressure rise in

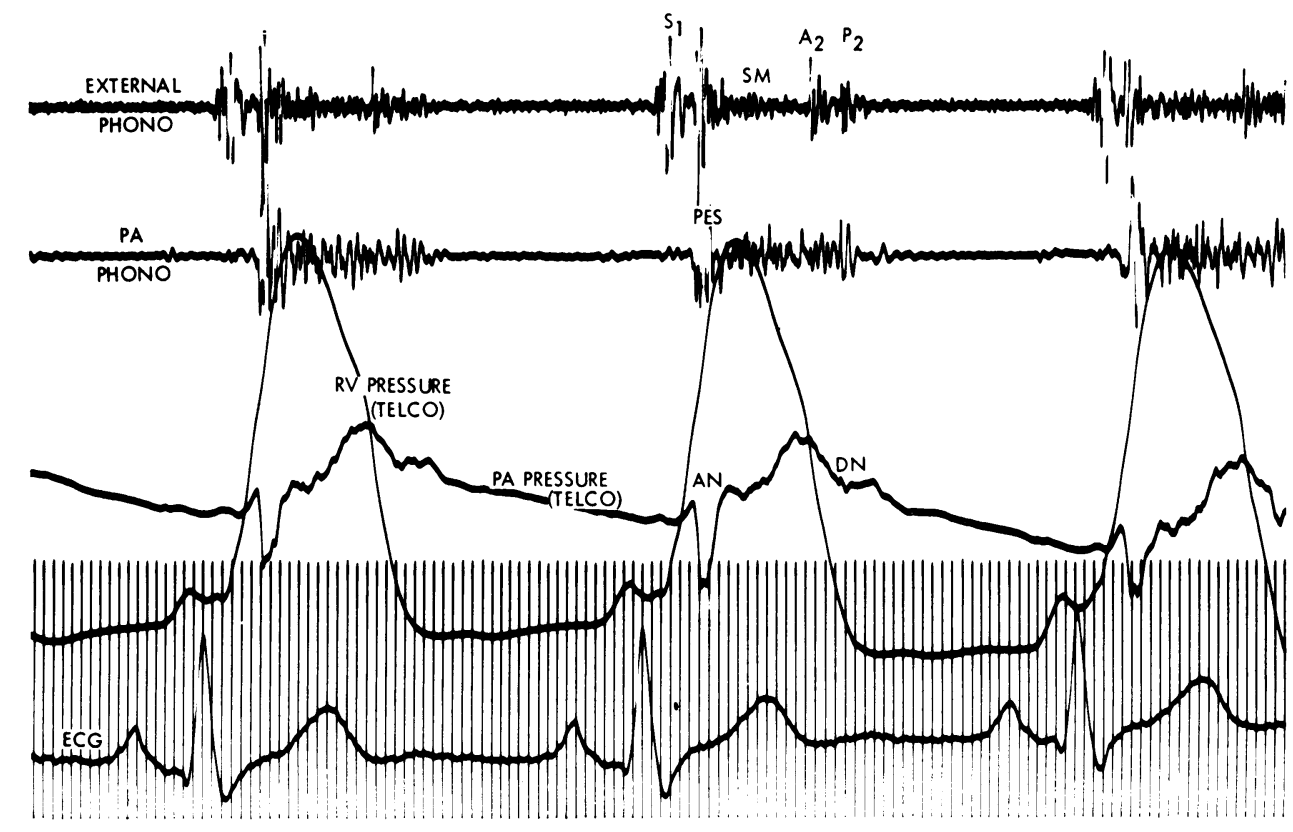

FIG. 8 External and pulmonary artery phonocardiogram showing an ejection sound (PES) in a patient with isolated valvular pulmonary stenosis. As in tetralogy of Fallot with valvular pulmonary stenosis, $P E S$ coincides with the anacrotic notch $(A N)$ on the pulmonary artery pressure $(P A)$ tracing. 


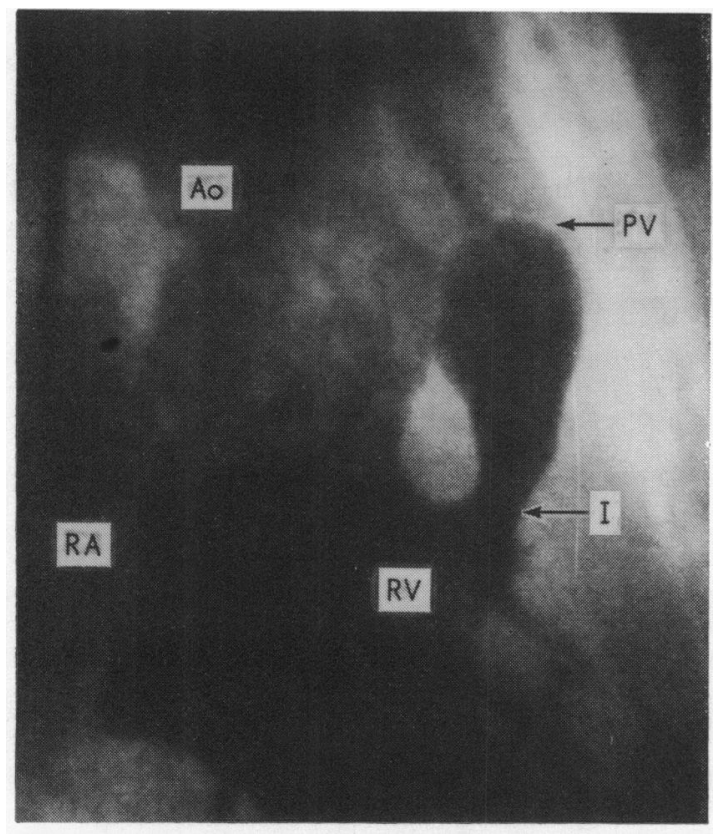

FIG. 9 Right ventricular angiogram in a patient (Case II) with tetralogy and pulmonary valve stenosis. The doming pulmonary valve $(P V)$ associated with an ejection sound is typical of pulmonary valve stenosis. There is also infundibular (I) narrowing. The aorta (Ao) is beginning to opacify as a result of right-to-left shunting through the large ventricular septal defect.

the central aorta. In contrast, aortic valve ejection sounds occur 20-40 msec after the onset of pressure rise, coincident with an anacrotic notch in the central aorta pressure trace (Whittaker et al., 1969). The ejection sound of isolated valvular pulmonary stenosis was shown to resemble that of valvular aortic stenosis in that it appeared $30-40 \mathrm{msec}$ after the onset of pulmonary artery pressure rise, coincident with the anacrotic notch on the pulmonary artery pressure tracing (Fig. 8). The ejection sound in tetralogy of Fallot was likewise shown to occur after the onset pressure rise, coincident with the anacrotic notch on the pulmonary artery pressure trace (Fig. 5). It was recorded poorly in the right ventricle and central aorta, but clearly in the pulmonary artery in keeping with its postulated pulmonary valve origin (Fig. 4).

In conclusion, ejection sounds may be more common than previously reported in adult patients with mild or moderate forms of tetralogy of Fallot or in whom the clinical course has been altered by previous palliative operations. In this setting, an ejection sound provides strong evidence for the presence of pulmonary valve stenosis. Though an ejection sound may be present in both, it should be possible at the bedside to distinguish between pulmonary valve stenosis with intact ventricular septum from that associated with mild or moderate tetralogy of Fallot. The lack of respiratory variation of the ejection sound, a small jugular venous a wave (Hoffman $e t$ al., I960), and diminution in intensity of the murmur with amyl nitrate inhalation (Vogelpoel et al., 1959), all favour the presence of tetralogy of Fallot with pulmonary valve stenosis.

\section{References}

Bing, R. J., Vandam, L. D., and Gray, F. D. (1947). Physiological studies in congenital heart disease. 2. Results of preoperative studies in patients with tetralogy of Fallot. Bulletin of the fohns Hopkins Hospital, 80, 12I.

Epstein, E. J., Criley, M., Raftery, E. B., Humphries, J. O., and Ross, R. S. (1965). Cineradiographic studies of the early systolic click in aortic valve stenosis. Circulation, 3I, 842.

Friesinger, G. C., and Bahnson, H. T. (1966). Tetralogy of Fallot. Report of case with total correction at 54 years of age. American Heart fournal, 71, 107.

Gamboa, R., Hugenholtz, P. G., and Nadas, A. S. (1964). Accuracy of the phonocardiogram in assessing severity of aortic and pulmonic stenosis. Circulation, 30, 35.

Gotsman, M. S. (1966). Increasing obstruction to the outflow tract in Fallot's tetralogy. British Heart fournal, 28, 615.

Higgins, C. B., and Mulder, D. G. (1972). Tetralogy of Fallot in the adult. American fournal of Cardiology, 29, 837.

Hoffman, J. I. E., Rudolph, A. M., Nadas, A. S., and Paul, M. H. (1960). Physiologic differentiation of pulmonic stenosis with and without an intact ventricular septum. Circulation, 22, 385.

Hultgren, H. N., Reeve, R., Cohn, K., and McLeod, R. (I969). The ejection click of valvular pulmonic stenosis. Circulation, 40, 631.

Lafargue, R. T., Vogel, J. H. K., Pryor, R., and Blount, S. J., Jr. (1967). Pseudotruncus arteriosus; a review of 21 cases with observations on oldest reported case. American fournal of Cardiology, 19, 239.

Leatham, A. (1958). Auscultation of the heart. Lancet, 2, 703.

Leatham, A., and Vogelpoel, L. (1954) The early systolic sound in dilatation of the pulmonary artery. British Heart fournal, 16, 21.

Leatham, A., and Weitzman, D. (1957). Auscultatory and phonocardiographic signs of pulmonic stenosis. British Heart Fournal, 19, 303.

McKusick, V. A. (1958). Cardiovascular Sound in Health and Disease, p. 185. Williams and Wilkins, Baltimore.

Perloff, J. K. (1964). Recognition and differential diagnosis of pulmonary stenosis. In The Theory and Practice of Auscultation, pp. 216-229. Ed. by B. L. Segal. F. A. Davis, Philadelphia.

Perloff, J. K. (1970). The Clinical Recognition of Congenital Heart Disease, pp. 364-365. W. D. Saunders, Philadelphia.

Reeve, R. (1966). Variations of the ejection click in valvular pulmonic stenosis. Clinical Research, 14, 129.

Thompson, M. E., Shaver, J. A., Heidenreich, F. P., Leon, D. F., and Leonard, J. J. (1970). Sound, pressure and motion correlates in mitral stenosis. American fournal of Medicine, 49, 436.

Vogelpoel, L., Nellen, M., Swanepoel, A., and Schrire, V. (1959). Use of amyl nitrite in diagnosis of systolic murmurs. Lancet, 2, 810. 
Vogelpoel, L., and Schrire, V. (1960a). Auscultatory and phonocardiographic assessment of pulmonary stenosis with intact ventricular septum. Circulation, 22, 55.

Vogelpoel, L., and Schrire, V. (I960b). Auscultatory and phonocardiographic assessment of Fallot's tetralogy. Circulation, 22, 73.

Whittaker, A. V., Shaver, J. A., Gray, S., III, and Leonard, J. J. (1969). Sound-pressure correlates of the aortic ejection sound; an intracardiac sound study. Circulation, 39, 475.
Wolferth, C. C., and Margolies, A. (1945). Heart sounds. In Diagnosis and Treatment of Cardiovascular Disease, 3 rd ed., p. 545. Ed. by W. D. Stroud. F. A. Davis, Philadelphia.

Requests for reprints to Dr. C. Edwin Martin, 7402 Presbyterian-University Hospital, 230 Lothrop Street, Pittsburgh, Pennsylvania 15213, U.S.A. 